\title{
Pop-up landscape architecture in Ho Chi Minh City: Cases of creating livable city for all
}

\author{
Anh Viet $\mathrm{Vu}{ }^{1}$, Thi Ai Thuy Pham ${ }^{1}$, and $T u$ Pham ${ }^{1, *}$ \\ ${ }^{1}$ University of Architecture Ho Chi Minh City, 196 Pasteurstr., Ward 6, District 3, Hochiminh City
}

\begin{abstract}
The pop-up architecture (or landscape architecture) becomes popular nowadays. Some highlights include annual architecture program such as the Serpentine Gallery Pavilion at Hyde Park, London; MPavilion in Melbourne; MoMA PS1 and Heart Sculpture in New York. Many of these pop-up architectural works have been designed by world renowned architects, such as Zaha Hadid, Rem Koolhaas, Hezorg and de Meuron, Jean Nouvel, Toyo Ito, SANAA, Shigeru Ban, BIG, etc. And many of these designs reflect innovative thinking that changes the professional world of architectural design. But above all, these pop-up architectures were created in responsive manner to the urban community and the community controversially has good response to this type of architecture. In the other words, pop-up architecture is the way the architects touch the heartbeat of the cities, make them livable for all. Ho Chi Minh City has its own types of pop-up landscape architecture, whereas this paper intends to explore in two case studies: Nguyen Hue Floral Boulevard and Nguyen Van Binh Book Street. Nguyen Hue Floral Street is celebrating now its twelfth birthday in the city. Nguyen Van Binh Book Street has just passed its first anniversary in 2017. Both cases live its own story behind the scene about how livable a city could be through place-making by architecture and landscape design. Throughout these cases, we would like to find out how this type of pop-up landscape architecture being realized and become popular in Ho Chi Minh City, and how it is devoted to a livable city for all.
\end{abstract}

\section{Introduction}

Should architecture be permanent: choices of the community?

Modern cities are growing together with the economic growth, accumulating achievements in construction technology to create wonderful works of architecture. Architecture in general and modern architecture in particular develops simultaneously with economic growth, accumulating technological achievements to create monumental structures. Architects seem to get more freedom in designing magnificent form and space by their own talent. Architects are so into the world of compositing techniques, freely creating illusory spaces and new and exciting forms with criteria of beauty, high quality, durability, and on a large scale. Urban space gets more and more great splendid architecture, but is it enough for a good place to live for everyone?

\footnotetext{
*Corresponding author: anh.vu@uah.edu.vn
} 
However, many of such constructions have to face difficulties in reality; the architects' ideas and the values defined by the builders sometimes are not accepted by the community. One recent example is the decision of the government of Manchester City, Britain, to demolish Piccadilly Gardens Pavilion after 13 years since its opening. This place is designed by Tadao Ando, the Pritzker laureate and the world-known Japanese architect. Pure concrete used to be the key language of Ando's architecture that made his fame has been largely denied by the Manchester citizen and tourists. The report from the Manchester authority has said, "Over the past few years, the City Council and Greater Manchester Police have been working together to tackle concerns regarding Piccadilly Gardens, particularly relating to anti-social behaviour, crime, and the maintenance and care of the public realm". Before this decision from the city, there was a petition signed by over 20,000 residents of the city that demanded "either demolishing or transforming its unloved concrete wall once and for all".
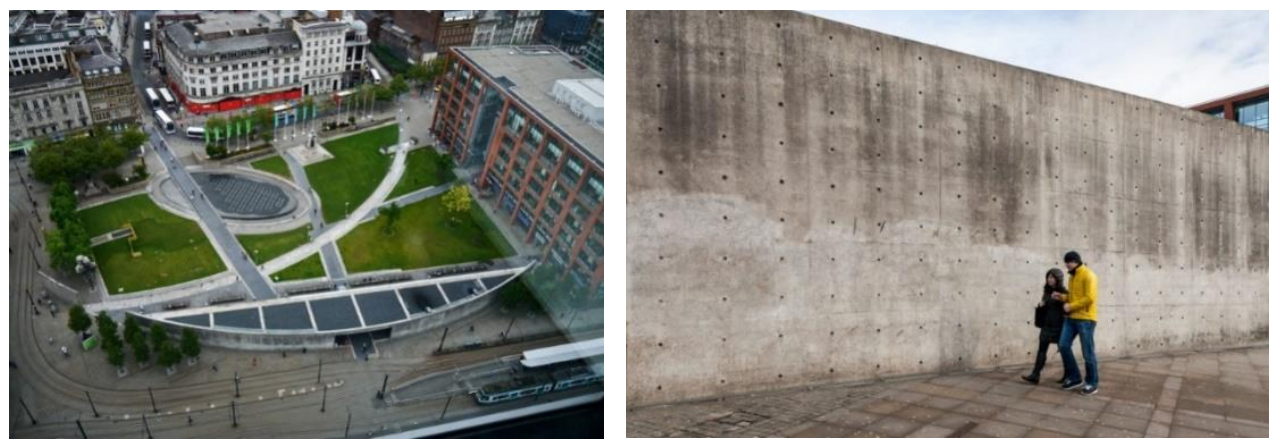

Fig. 1. The Piccadilly Gardens Pavilion in Manchester and its pure concrete wall - the main cause of the public anti-behaviour to this architectural design by Tadao Ando.

Aside from the two conceptions of "art for art's sake" and "art for human's sake" from this story, a rule has been drawn out that the pre-determined ideas of architects put on their design are not always on the same side with community's needs. Therefore, the design ideas sometime are swept away by the reality. In other words, the self-arbitrary character of architecture sometime makes it frontward or backward to the public interest. The architect's competence now is required to get them more involved to human scale and to uniformity with the landscape.

In addition, urban dwellers under the pressures of modern life tend to be against pure concrete, glass and steel structures, which are unlikely to change in their daily lives. The permanent character of architecture sometimes makes it "bore" to the public. Architects used to be acquainted with sort of permanent architectures. It means they mostly deal with three dimensions static space, but time is really matter to people. It is the fourth dimension that very important to make human space truly live. Architects should appreciate the adaptation and over time variability of the structures in order to contribute to the greater good, especially in modern metropolises. A familiar urban space suddenly changes one day with a new interesting landscape architecture become a good way to make people feel their city beats. That is the reason why pop-up architecture becomes popular nowadays.

Paper size A4. Margins: top, bottom, left and right $-1.8 \mathrm{~cm}$, footer $-1 \mathrm{~cm}$ article Title font Bukman Old Style, 14. All text is Times New Roman, font size 10, single spacing, first line of all paragraphs indented.

Introduction defines the nature and extent of the problems studied, relates the research to previous work (usually by a brief review of the literature clearly relevant to the problem), ("Studies showed that ..."), or ("Studies have shown that ..."). Introduction explains the objectives of investigation ("The objective of the current study was...") and defines any specialized terms or abbreviations to be used in what follows. Introduction 
logically leads to the hypothesis or principal theme of the paper. Do not repeat well-known facts, nor state the obvious.

\section{Literature review}

A new approach to the public architectural interest.

Recently, a new architectural type is emerging in the world, especially in public urban places that call pop-up architecture. The article "Pavilions, Pop Ups and Parasols: The Impact of Real and Virtual Meeting on Physical Space" [1] has made a definition that this architectural style "is a progressive architecture is being commissioned to promote open- ended, undetermined, lightly programmed or un-programmed interactions between people". Along with rapidly changing social relationship flowing from social media such as Facebook, Twitter, and Instagram, urban citizen become more interested in this new type of architecture and landscape architecture.

May be "pop-up architecture is the entertainment of today but will be the urban destination of tomorrow" said Lisa Rochon on the Globe and Mail [2]. She commented "It's light, lyrical and cheap to construct. Permanent, masonry-heavy architecture will continue to drill down into the ground, but architecture as light as Twitter can risk more - beginning with the need to invigorate neglected or marginalized public space right now". Therefore, most of pop-ups architecture was born with intention to enliven public places.

The reason why pop-up architecture become more popular not only because of its audiences but also its creators. Normally when the architect deals with traditional, permanent architecture, they must face and satisfy the huge demands from many stake-holders, such as the city authority, the investor, the financial backers, the building owners, the building codes and multiple users. By contrast, pop-up architecture can advance a singular purpose and concentrate its impact. With these advantages, pop-up architecture is considered to be avantgarde react to traditional permanent architecture, and lauded for its progressiveness. Temporary themselves, pop-up structures let the architects and designers have more freedom to experiment their creativity in reality fast and effective.

Allison Arieff, former editor-in-chief of architecture and design magazine Dwell, explains that today's pop-up design is "a bold expression of unfettered thinking and creativity" [3]. Indeed, pop-up, temporary, and mobile architecture have often sat well outside the boundaries of mainstream architecture, pushing the edge of progressive design. Architectural ideas that as a practical matter couldn't be built as permanent structures are possible as temporary structures.

Thus, it is reasonable that pop-up architecture often are the creations of young architects who, their talent and energy outrunning their employment opportunities. The young architects take these chances to initiate, design and build their glimpses of what a better city - more open, more social, more pleasurable, more surprising. And their final products, popup architectures are always full of energy, accumulating the creativity to open a new approach in design.

Besides, pop-up architecture has also become more popular for practical reasons, particularly the need for affordable, easily assembled housing in the wake of natural disasters. Hurricane Katrina in 2005; Haiti's catastrophic earthquake in 2010; Japan's 2011 Tōhoku earthquake, ensuing tsunami, and Fukushima nuclear plant meltdown-natural disasters throughout the 2000s have left hundreds of thousands of individuals displaced in their wake. And it is the time for the architect to devote their effort and ability to the community. For example, Japan-based Shigeru Ban Architects constructed emergency shelters built of paper in Haiti after seriously earthquake, as well as a temporary housing encampment built from storage containers in Onagawa, Japan, following the tsunami and nuclear accident at 
Fukushima. In fact, in post-disaster areas, pop-up architecture aims to provide more than shelter, but a real pragmatic place to launch new urban life $[4,5]$.

With these above critics, people may see pop-up architecture is a totally new trend of the 21 st century architecture. But in the article "The Rise and Rise of Pop-Up Architecture" [3], Marni Epstein-Mervis has pointed out that the development of pop-up architecture has been an idea of over 2000 years ago, tracing back from its origins in ancient Rome.

The latest example and perhaps the world's best-known piece of pop-up architecture was constructed as an archway to mark the entrance to the 1889 World's Fair, the Exposition Universalle in Paris: Eiffel Tower. At first, after the exposition, this tower was just only meant to stand for 20 years following Parisians' approval. But then because the 984-foot tower could send and receive distant radio transmissions, it was appropriated as a radio antenna tower by France's Department of Military Engineering and escaped from its planned demolition. Now it is still there, permanently is the symbol of Paris and France.

Therefore, pop-up architecture also reminds us that built space is always in motion, always prone to being readapted and reimagined. It should also be noted that, in a parallel universe, the commitment of talented architects might be spent on things like housing, schools or permanent transformations of cities. There is a correlation between the rise of popups on the one hand and on the other, the rise of very large architectural practices, run on industrial lines, which shape the places where most of us spend most of our lives [6].

By the nature of pop-up architecture, architects use temporary pleasures to make permanent changes to the way people can inhabit their neighborhoods. What used to be temporary pop-up today may be the permanent and compulsory character of the architecture tomorrow.

From that point of view, this paper analyzed a series of case studies from west to east to identify the main-stream of pop-up architecture now and then see what could be the mainstream of tomorrow architecture, to create livable place for human $[7,8]$.

\section{Case studies: from western cities}

The most well-known example of pop-up architecture is Serpentine Gallery Pavilion which is annually built at Hyde Park, London since 2000 (then later MPavilion in Melbourne since 2014). The Serpentine Gallery Pavilion has brought in an impressive array of international architects over the years. We could name a list of masters in architecture that used to design this eventual architecture like Zaha Hadid (2000), Daniel Libeskind (2001), Toyo Ito (2002), Oscar Niemeyer (2003), Alvaro Siza and Eduardo Souto de Moura (2005), Rem Koolhaas (2006), OlafurOliasson (2007), Frank Gehry (2008), SANAA (2009), Jean Nouvel (2010), Peter Zumthor (2011), Hezorg and de Meuron (2012), Sou Fujimoto (2013), Smiljan Radic (2014), SelgasCano (2015), BIG (2016), Francis Kére (2017). Some architect has been famous before designing this pavilion but many of them has reached their peak of fame after this construction. The truly common character that made Serpention Pavilion so famous is the innovative and breakthrough in every annually architecture design. 

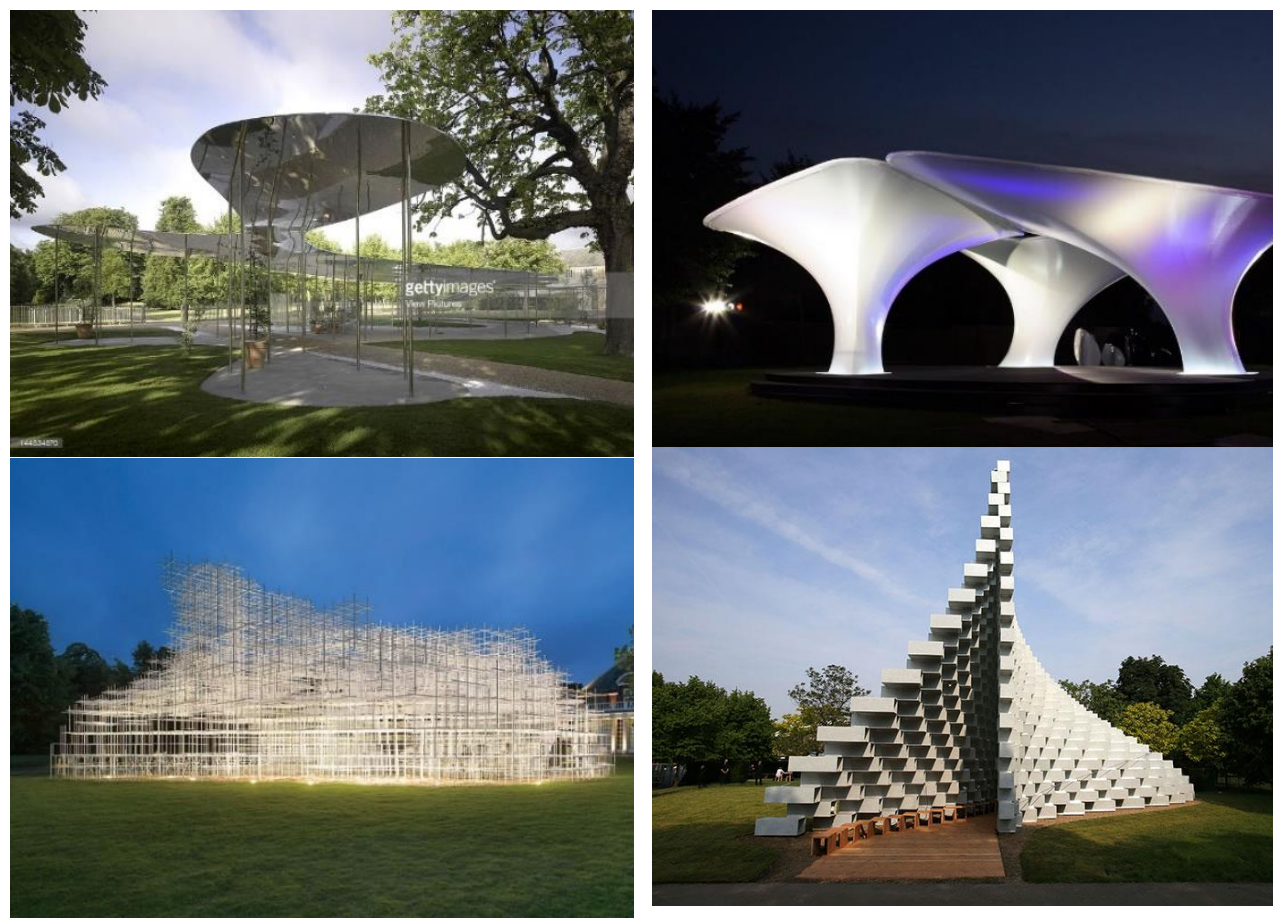

Fig. 2. Serpentine Pavilion at Hyde Park, London.

Beside the pure form of temporary construction, the pop-up architecture also present in many other forms likes flower and garden festivals, street installation art, lighting art, urban design. We can Examples are famous structures such as PARK-ing day project in San Francisco; Floating Cinema and Chelsea Flower Show in London; MoMA PS1 program in New York; International Garden Festival in France; iLight Marina Bay in Singapore; or World Architecture Exposition, World Floriade Exposition, etc. These eventually architecture and landscape architecture all are chance of designers to freely create and to test new ideas for serving the community. Every special architecture and landscape structures mentioned above convey particular themes; they're attractive in their own way while designed with the same purpose of serving the urban dwellers. This type of work stimulates the designer's creativity on one hand, and strongly interacts with the community on the other. It mobilizes resources to make ideas happen while gets responses of experiencing from the metropolitans, helping the people enhance their senses of truth, goodness, and beauty [9]. 

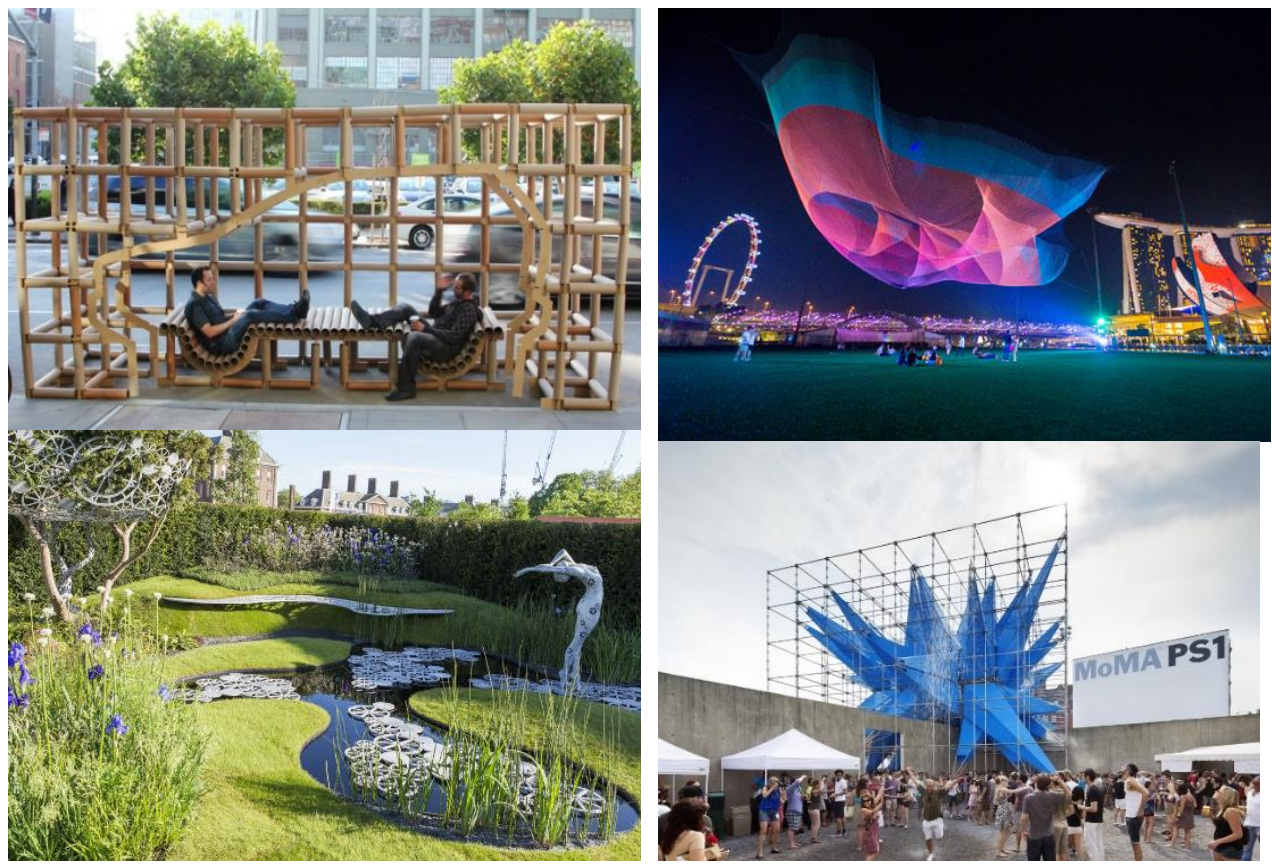

Fig. 3. Some of landscape-event structures worldwide: PARK-ing day, Chelsea Flower Show, MoMA PS1, iLight Marina Bay.

Getting through these above references in systematically synchronizing, we could recognize the most striking common feature, which distinguishes the pop-up architecture from other types of architectural and landscape design: temporary and eventually. This nature of pop-up architecture has created challenges for architects to design as follows:

Firstly, the design solution must not break the current situation. At the end of the event, the place where the event was restored is in the status quo.

Secondly, because construction time is very limited, the design solution must be prioritized for pre-processing, just quick assembly at the construction site.

Thirdly, often works exist for a certain period of time, so the investment costs are not high, which means that the materials used are easy to find, low cost or recyclable.

Fourthly, is the continuity of innovation. Due to the fact of events or periodic (annual), each time to re-implement the works, architects need to promote all levels of creativity and innovation to not repeat what was in the current situation, or has been determined in public taste. It is the personality of the designer who constantly innovates in architecture combined with the traditional cultural material through natural landscape elements that will create the uniqueness and attractiveness of this type to the community.

\section{Cases of Ho Chi Minh City}

a. $\quad$ Nguyen Hue Flower Street - a specialty of Tet

To express one's love and respect, bouquets of flowers are given to each other. To honor a livable city, it is reasonable to have a street of flowers for the citizen.

An urban landscape design by floral decoration is a way to memorize special moment to urban residents. At that moments and in these landscape setting, people feel the beat of their urban lives, cheering the meaningful urban place together. Many cities in the world has flower festival, firework festival, lighting festival to celebrate their urban culture. And 
likewise, Ho Chi Minh City has been a leading city in the Vietnam to introduce Nguyen Hue Flower Street which signifies a momentous pop-up landscape architecture in Vietnam. From a societal view, Nguyen Hue Flower Street has become a vital part of the recreational activities for Ho Chi Minh City residents. The demand to enjoy this pop-up landscape architecture is evident in thousands of people visiting every year. Not only limited in Ho Chi Minh City, this type of landscape architecture has widely spread over many other provinces in Vietnam like My Tho, Can Tho, Da Nang, Da Lat, Quang Ngai, etc. It could be said that this type of pop-up architecture has developed into a new culture of the modern urban life.
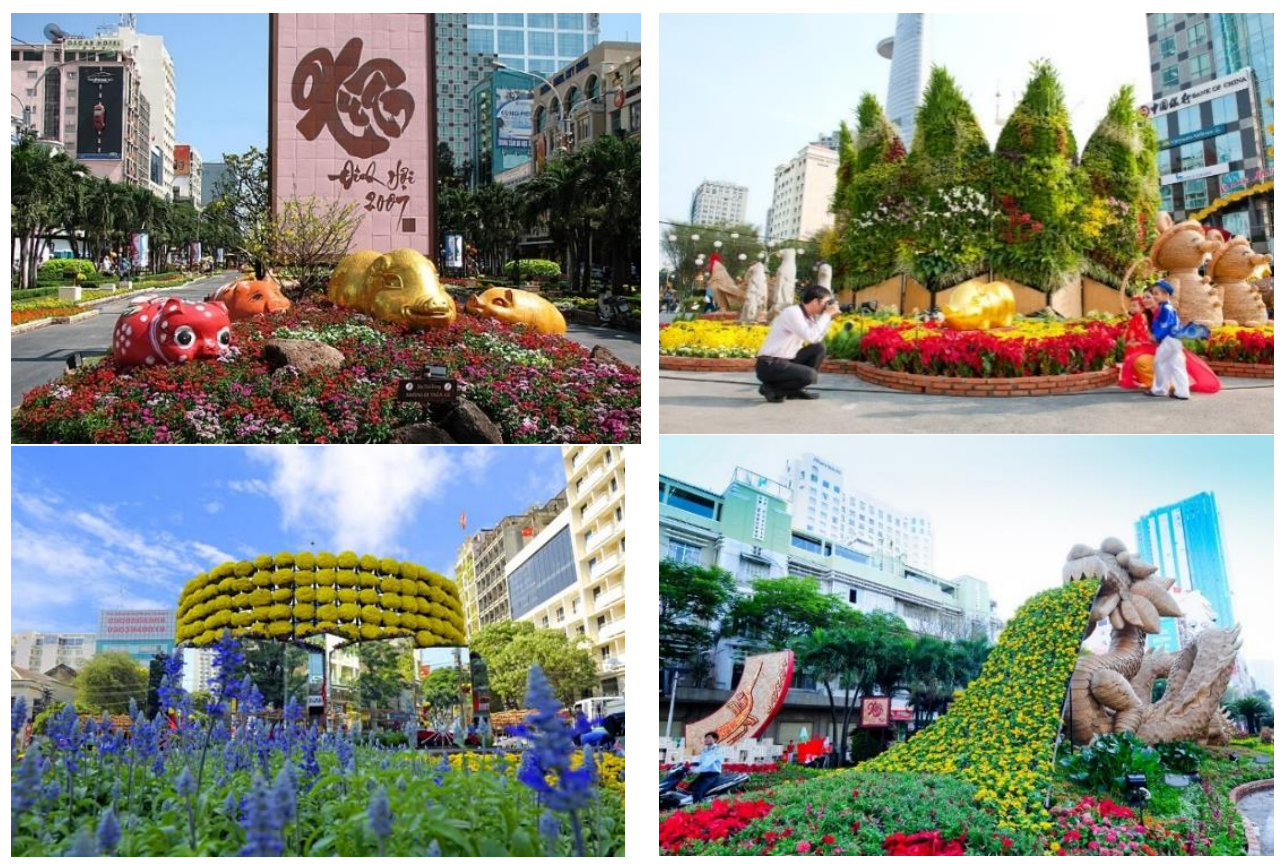

Fig. 4. Nguyen Hue Floral Streets design in 2007, 2009, 2012, 2013.

The community is in favor of Nguyen Hue Flower Street, first and foremost, due to its significance moment. Once a new year comes, everybody would like to have a place to relax, to enjoy with their family, and to take photos to remark a year has passed and a new year has come. Nguyen Hue Flower Street is, thus, to satisfy that need. In addition, the flexible solutions to architecture and landscape are crucial as well. The traditional Tet occasion brings ideas of material and inspiration to designers, including conventional elements and chances of creativity from the traditional basis. These simple materials such as thatch, rattan, bamboo, leaves, pottery, terracotta, etc. have gained its attractiveness nowadays. They used to be familiar to Vietnamese farmers who are now residing in big cities with tons of concrete, steel and glass structures. These materials, which are common, inexpensive and colorful flowers, are arranged in different layouts to create their distinct themes. The themes can be fairy tales, folklores, the peculiar cultural features of each region, the current events and so on, to help develop the message of the design. There is always a theme of a specific Oriental zodiac of each year at Nguyen Hue Flower Street. The zodiac forms the idea to construct the welcoming gateway and the entirely design work. For instance, the Tiger is associated with jungle and mountain while the Cat is related to houses, and so on. The flexible design, which conveys the traditional elements to modern contexts, can probably produce fruitful results for the application of the community-based landscape architecture in Vietnam. This kind of 
construction has its own unique characteristics that cannot be found in any other public structures in Vietnam.

a. Nguyen Van Binh Book Street in HCMC - honoring the reading culture
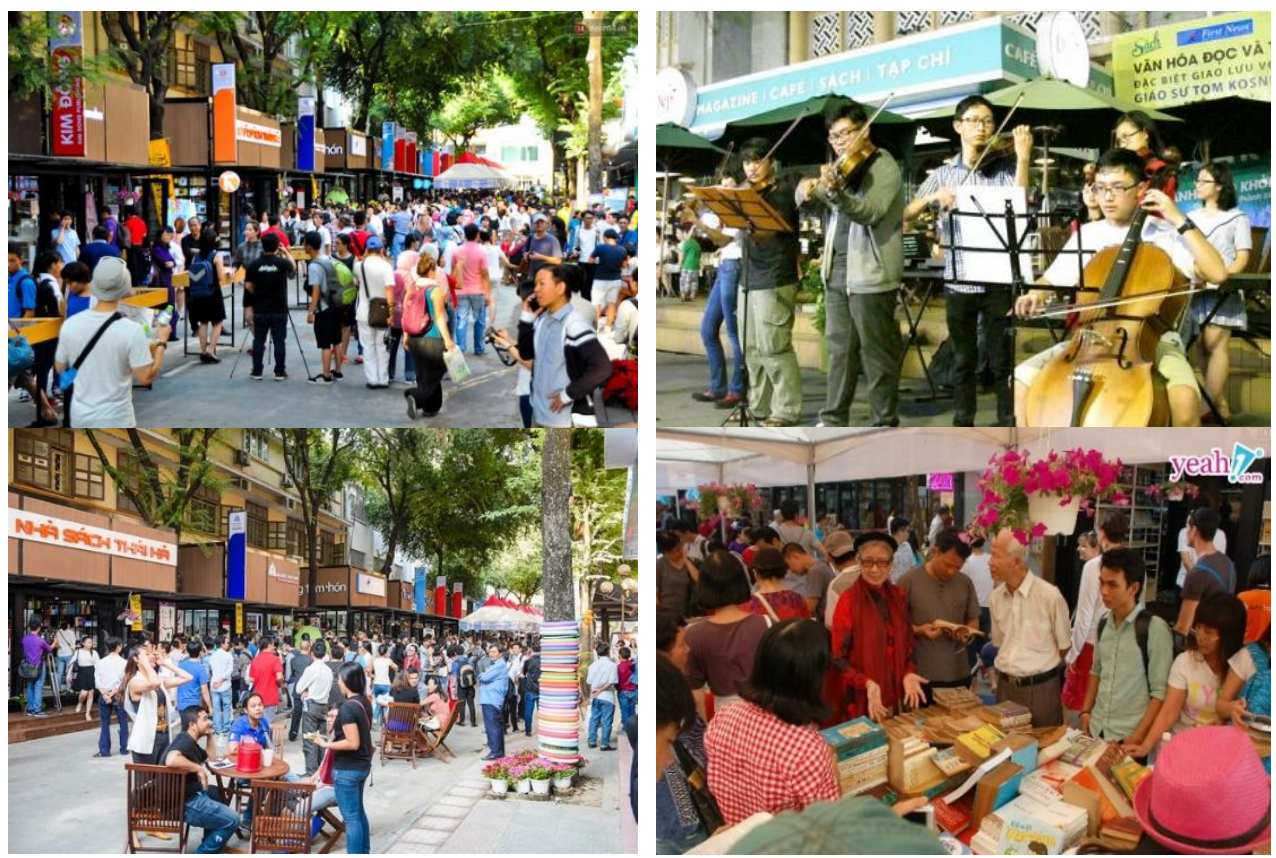

Fig. 5. Public interest and activies on Nguyen Van Binh Street Book, Ho Chi Minh City.

This urban landscape design project gets over a temporary construction to become a longlasting one. In 2016, a group of publishing house gather with the architect and city authority to find a place to create a public space for books, to honor the reading culture. Then a popup landscape architecture emerging from a quiet and narrow street surrounded by heritage buildings likes the Notre Dame Cathedral and the Post Office Headquarter of Ho Chi Minh City. Situated on such great site but this street is just the backside of buildings along the street, used to be a parking lot. The only attractive feature of this site at that time was for wedding photos because of its stunning alleys of trees. Within 2 months prior to the Tet holiday in 2016, the space has been transformed into a landscape architectural construction for book lovers: Nguyen Van Binh Book Street in Ho Chi Minh City.

Architecturally, the Book Street was constructed to consolidate the design variations and simplicity so as to optimize its functions and applications. Selected materials attach importance to create warmth and familiar atmosphere such as: wood, brick, ceramic tiles. The openness is maximized by glass and steel frame give the free space for books present themselves. The entire structure and architecture of the stalls is taken from a combination of 4 squares, a synchrony with the side of Ho Chi Minh City Post Office on the opposite side of the street.

Though just only born, this pop-up architecture is now not only the space for bookstores, publishers but a valuable public place for city residents and tourist, attract thousands of visitors monthly. If you are just buying books, Ho Chi Minh city has a lot of options, with more books, better prices, and equally beautiful architecture. But people still choose to Book Street because of its specialty, friendly atmosphere, which carefully create by architectural language. The attraction of this type is not only in the form of space but also in the spirit of the place it carries. 
In order to realize the Road Book, the design team has just less than 2 months for all the stages of designing and executing architecture and interior design together with the organization and inviting the participation of accompanying publishing house. This is not just design and build but also the sum of the total force on many aspects:

- Legal: ask for permission of the City authority (Department of Information and Communication, People's Committee of District 1, Department of Planning and Architecture, Department of Construction, ...)

- Design: solution to meet the guiding criteria of the departments of the city, while ensuring the construction of fast, neat, without affecting the infrastructure and go parallel with the process of construction.

- Execution: pre-fabricated workshop, shallow foundation on site, location and installation on site, coordination between construction units simultaneously

- $\quad$ Finance: The cost has to be reasonable and collect all business units' contribution to both the booth and the overall public space

- Public relations: coordination between design and communication channels from the beginning to attract the attention of the community; at the same time building up event calendar organized on the book street to attract the community.

Unlike the "spontaneous" public spaces normally happens in urban areas, this is a "designed" actions that sums up the practical elements of urban design, landscape architecture, harmoniously coordination of all stakeholders, including government authority, agencies, investors, business sector and public user to implement. This could not be done solely by architects through design but need a holistic approach, gathering all resources. From a general concept to have a pop-up architecture for books, Ho Chi Minh City now has a permanent public space, meaningful place for all.

\section{Conclusion}

Pop-up architecture and landscape architecture become popular in urban scene not just a temporary trend but a real permanent interest of urban community. This type of architecture is a truly effective tool for place-making, which has been proved through many case studies around the world. Ho Chi Minh City has also quite been successful with two cases: the Nguyen Hue Boulevard and the Nguyen Van Binh Book Street. Each cases has each own recipe but the process and outcome in general are the same. The way architects get involved in pop-up architecture and landscape architecture is the way the professional and the public get together in actual actions for creating livable places for all. Pop-up architecture projects are chances for architects to try their new ideas, concepts, or philosophy and they are also chances for urban community to enjoy their lives in a different way, more diverse, unique and livable.

\section{References}

1. L. Van Schaik, F. Watson, Pavilions, Pop Ups and Parasols: The Impact of Real and Virtual Meeting on Physical Space, AD Magazine (2015)

2. L. Rochon, The Power of pop-up architecture, https://www.theglobeandmail.com/arts/art-and-architecture/the-power-of-pop-uparchitecture/article4267683/

3. M. Epstein-Mervis, The Rise and Rise of Pop-Up Architecture - How temporary design became mainstream, http://www.curbed.com/2016/3/9/11180920/architecture-historytemporary-banksy 
4. R. Moore, The pop-up designs changing the city landscape, https://www.theguardian.com/artanddesign/2013/aug/03/pop-up-designs-architecturelondon

5. TA Landscape Architecture, Flower Street, http://talavn.com.vn/en/tala/flower-street

6. TA Landscape Architecture, Nguyen Van Binh book street, http://talavn.com.vn/en/hcm-city-book-street-on-nguyen-van-binh-street

7. Vũ Việt Anh, Khổng Minh Trang, Vietnamese Architecture Magazine 10, 59 (2013)

8. Vũ Việt Anh, Khổng Minh Trang, Vietnamese Architecture Magazine 12, 22 (2011)

9. Vũ Việt Anh, Phạm Thị Ái Thủy, The art of designing public space in related to organizing festival in Quy Nhon City, Conference Proceeding "Urban Planning Concept to develop Quy Nhon City toward 2030 and vision to 2050" 